\title{
Studies on Characterization, Optical Absorption, and Photoluminescence of Yttrium Doped ZnS Nanoparticles
}

\author{
Ranganaik Viswanath, ${ }^{1}$ Halehatty Seethya Bhojya Naik, ${ }^{1}$ \\ Yashavanth Kumar Gubbihally Somalanaik, ${ }^{1}$ Prashanth Kumar Parlesed Neelanjeneallu, ${ }^{1}$ \\ Khandugadahalli Nagarajappa Harish, ${ }^{1}$ and Mustur Channabasappa Prabhakara ${ }^{2}$ \\ ${ }^{1}$ Department of Studies and Research in Industrial Chemistry, School of Chemical Sciences, Kuvempu University, \\ Shankaraghatta 577 451, India \\ ${ }^{2}$ Department of P.G. Studies and Research in Industrial Chemistry, Sir. M.V. Government Science College, \\ Bommanakatte, Bhadravathi, Shimoga, Karnataka 577302, India
}

Correspondence should be addressed to Halehatty Seethya Bhojya Naik; hsb_naik@rediffmail.com

Received 5 July 2013; Revised 9 December 2013; Accepted 30 December 2013; Published 13 February 2014

Academic Editor: E. Goldys

\begin{abstract}
Copyright (c) 2014 Ranganaik Viswanath et al. This is an open access article distributed under the Creative Commons Attribution License, which permits unrestricted use, distribution, and reproduction in any medium, provided the original work is properly cited.
\end{abstract}

\begin{abstract}
Pure ZnS and ZnS:Y nanoparticles were synthesized by a chemical coprecipitation route using EDTA-ethylenediamine as a stabilizing agent. X-ray diffraction (XRD), high resolution transmission electron microscopy (HRTEM), field emission scanning electron microscopy (FE-SEM), Fourier transform infrared spectrometry (FTIR), thermogravimetric-differential scanning calorimetry (TG-DSC), and UV-visible and photoluminescence (PL) spectroscopy were employed to characterize the assynthesized $\mathrm{ZnS}$ and $\mathrm{ZnS}: \mathrm{Y}$ nanoparticles, respectively. XRD and TEM studies show the formation of cubic ZnS:Y particles with an average size of $\sim 4.5 \mathrm{~nm}$. The doping did not alter the phase of the zinc sulphide, as a result the sample showed cubic zincblende structure. The UV-visible spectra of $\mathrm{ZnS}$ and $\mathrm{ZnS}: \mathrm{Y}$ nanoparticles showed a band gap energy value, $3.85 \mathrm{eV}$ and $3.73 \mathrm{eV}$, which corresponds to a semiconductor material. A luminescence characteristics such as strong and stable visible-light emissions in the orange region alone with the blue emission peaks were observed for doped $\mathrm{ZnS}$ nanoparticles at room temperature. The PL intensity of orange emission peak was found to be increased with an increase in yttrium ions concentration by suppressing blue emission peaks. These results strongly propose that yttrium doped zinc sulphide nanoparticles form a new class of luminescent material.
\end{abstract}

\section{Introduction}

Nanomaterials and nanostructures play the important role in applications of nanoscience and nanotechnology in the fields of energy sources, environments, and health. Nanomaterials are increasingly gaining the attention of not only the scientific community but also the public due to their unique properties, which lead to new and exciting applications $[1,2]$. For the last few years the investigation has been focused on the preparation and characterization of II-VI semiconductor nanoparticles for applications in biological field as molecular probes or biolabels [3] and also have attracted much attention in photo- and electroluminescence properties because of their size-dependent (which is tunable) and have promising optoelectronic applications [4]. Among these families, a nontoxic semiconductor zinc sulfide $(\mathrm{ZnS})$ is one of the most important and typical crystalline phosphors for both applications and basic research. In particular, dopedZnS phosphors have been investigated extensively, because $\mathrm{ZnS}$ a good host material is an important versatile and luminescent material with a wide band gap $(3.6 \mathrm{eV})$ [5]. The optical properties of various $\mathrm{ZnS}$ doped nanocrystals and the potential applications of these luminescent materials have been reported by different groups [6]. ZnS nanoparticles in their doped and codoped form with transition and innertransition metals have received much attention as a class of particularly luminescent materials. Different metal ions such as $\mathrm{Cu}, \mathrm{Mn}, \mathrm{Pb}, \mathrm{Co}, \mathrm{Cd}, \mathrm{Eu}$, and $\mathrm{Sm}$ doped with $\mathrm{ZnS}$ have been studied by many researchers because of their extensive photoluminescence (PL) properties [7]. Generally ZnS doped 
with these metal ions provide new opportunities as full-color luminescence in the UV-visible region [8-12]. Recent studies on $\mathrm{Y}$ ions incorporated into wide band gap semiconductor like $\mathrm{ZnO}[13,14]$ which resulted in significant increase in the optical properties, photocatalyst efficiency with improved stability of $\mathrm{ZnO}$ nanoparticles. Yttrium doping has also resulted in the deep-level emission with strong enhancement in the UV emission intensity, which prompts the application of $\mathrm{ZnO}$ nanoparticles in full-color displays and photoelectric nanodevices [15]. Yttrium doping also tunes the emission wavelength of $\mathrm{ZnO}$ and makes a supersensitive UV detector [16]. In particular the available experimental data on Y:ZnS system to date is not known to the best of our knowledge. The potential applications and importance of Y doped IIVI semiconductors in optoelectronic and spintronic devices have motivated the present authors to undertake yttrium doped ZnS system for this study. A variety of methods have been proposed to obtained undoped and doped nanometer-sized zinc sulfide nanoparticles, including gasphase, solid/vapor, and aqueous solution reactions [4], and also different methods have been reported for the synthesis of zinc sulfide as a host for transition and rare earth metal ions [17]. Therefore, it is important to find a simple preparation method or process due to the complexity, expensiveness, and the use of a toxic gas, which can produce size controlled nanoparticles at lower cost with less or no impurities. So, here we describe the chemical coprecipitation method as it does not demand any costly apparatus building, process simplicity, effectiveness of doping, low impurity and higher yield.

In this paper, an effort has been made to synthesis $\mathrm{Y}^{3+}$ doped $\mathrm{ZnS}$ nanoparticles through simple chemical coprecipitation route using EDTA-ethylenediamine as stabilizing agent. Herein we have reported the optical and photoluminescence characteristics of semiconductor $\mathrm{ZnS}$ nanoparticles doped with yttrium ions. In the present work, structural and morphological properties have been studied by X-ray diffraction (XRD), transmission electron microscope (TEM), field emission scanning electron microscopy (FESEM), and fourier transform infrared spectroscopy (FTIR).

\section{Experimental Details}

2.1. Materials. Zinc nitrate $\left(\mathrm{Zn}\left(\mathrm{NO}_{3}\right)_{2} \cdot 6 \mathrm{H}_{2} \mathrm{O}\right)$, yttrium nitrate $\mathrm{Y}\left(\mathrm{NO}_{3}\right)_{3} \cdot 6 \mathrm{H}_{2} \mathrm{O}$, sodium sulphide $\left(\mathrm{Na}_{2} \mathrm{~S} \cdot 9 \mathrm{H}_{2} \mathrm{O}\right)$, EDTA-ethylenediamine, and all chemicals used in this work were of AR grade and used as received without further purification. Ultrafine deionized water was used throughout the experiment.

2.2. Nanoparticles Synthesis. Pure ZnS and ZnS:Y nanoparticles were prepared by chemical coprecipitation method in air atmosphere using EDTA as stabilizing agent. In a typical procedure, $0.5 \mathrm{M}$ zinc nitrate and yttrium nitrate with different concentration (0.025-0.1) in molar ratio were dissolved in $50 \mathrm{~mL}$ of distilled water-ethanol (equal volume) and stirred for $10 \mathrm{~min}$ at $80^{\circ} \mathrm{C}$ in a round bottom flask, as a sulfur source $0.5 \mathrm{M} \mathrm{Na} 2 \mathrm{~S} \cdot 9 \mathrm{H}_{2} \mathrm{O}$ was dissolved in $50 \mathrm{~mL}$ of distilled water-ethanol (equal volume) which was added

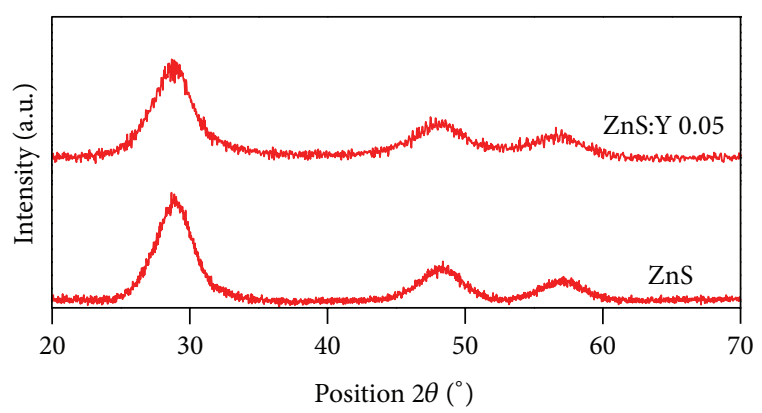

FIGURE 1: X-ray diffraction of the pure ZnS and ZnS:Y.

dropwise to the above solution and stirred for $15 \mathrm{~min}$. As a result the color of the solution changes to white. Then $50 \mathrm{~mL}$ of ethanol was added to above solution under stirring followed by the addition of 1 gram EDTA of $10 \mathrm{~mL}$ solution drop by drop and the resulted solution was stirred for 2 hours at $80^{\circ} \mathrm{C}$. The solution was cooled at room temperature and the resulting precipitate was centrifuged. The obtained dispersions were washed several times by distilled water and alcohol to remove the impurities, including traces of EDTA and the original reactants, if any. Finally the wet precipitate was dried in hot air oven at $80^{\circ} \mathrm{C}$ for $24 \mathrm{hrs}$.

2.3. Characterization Techniques. X-ray diffraction (XRD) patterns of the powder sample were collected on Phillips X'PERT XRD powder diffractometer (Phillips, PW-1800) using a radiation $\mathrm{CuK} \alpha$ with $1.54 \AA$ wavelength $(40 \mathrm{~mA}$, $45 \mathrm{kV}$ ), with $2 \theta$ range from $20^{\circ}$ to $70^{\circ}$. Structure and surface morphology was studied by field emission scanning electron microscopy (FESEM-Carl Zeiss, Supra 40VP). The morphology and size of the nanoparticles were studied using transmission electron microscope (TEM), which was performed at $200 \mathrm{keV}$ using JEOL JEM2010. Fourier transform infrared spectroscopy (FTIR, Shimadzu 8400 S Model) of the powder sample was recorded in the range of $4000-400 \mathrm{~cm}^{-1}$ at room temperature in $\mathrm{KBr}$ pellets. After ultrasonification in ethanol the optical absorption spectrum was recorded by UV-visible spectrophotometer (Shimadzu-Pharmaspec1600). The photoluminescence spectrum of the as-prepared sample was obtained over a range $300-800 \mathrm{~nm}$ using RF5301 Fluorescence spectrophotometer equipped with a $150 \mathrm{~W}$ Xenon lamp as the excitation source. Spectra was recorded using monochromator slit widths of $5.0 \mathrm{~nm}$ on both excitation and emission sides. Thermogravimetric analysis (TGA) was performed on Perkin-Elmer TGA7. Differential scanning calorimetry (DSC) was performed on a NETZSCH.

\section{Results and Discussion}

3.1. X-Ray Diffraction Analysis. Figure 1 shows the X-ray diffraction spectra of pure $\mathrm{ZnS}$ and $\mathrm{Y}^{3+}$ doped $\mathrm{ZnS}$ nanoparticles. The XRD patterns of both undoped and yttrium doped $\mathrm{ZnS}$ showed three main diffraction peaks indexed at (111), (220), and (311) which correspond to the planes of cubic zinc blende structure, respectively. These XRD patterns are well 


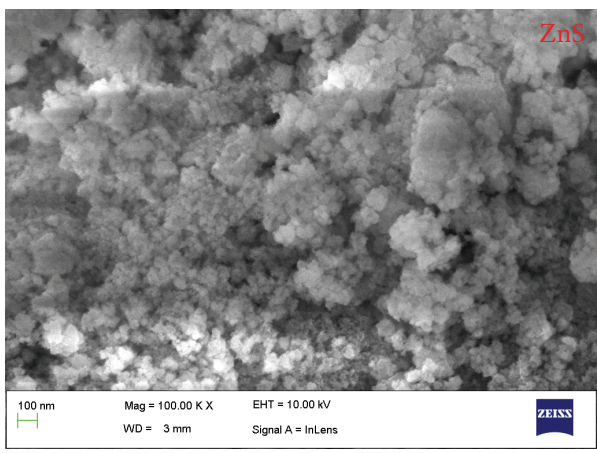

(a)

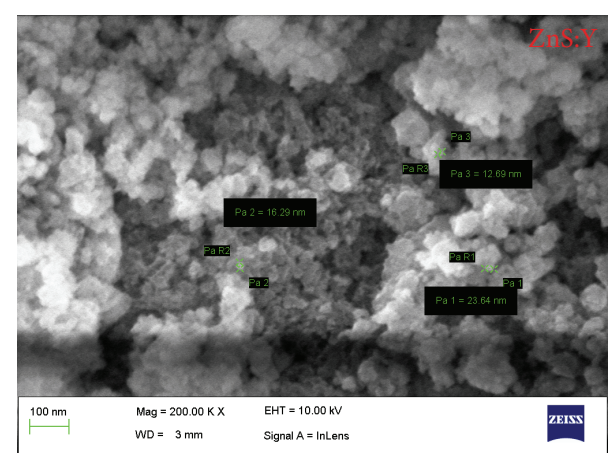

(b)

Figure 2: FESEM image of pure $\mathrm{ZnS}$ and $\mathrm{ZnS}: \mathrm{Y}$.

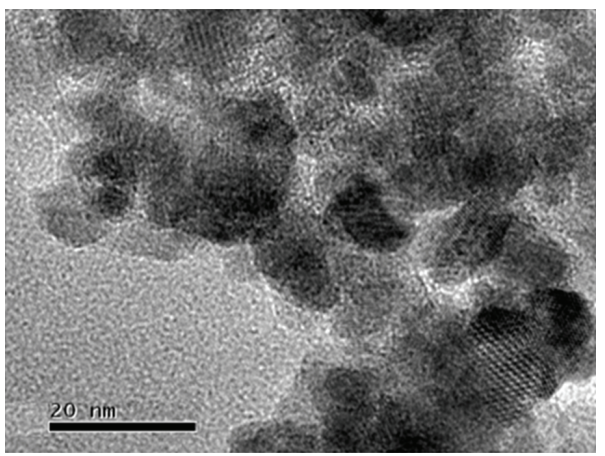

(a)

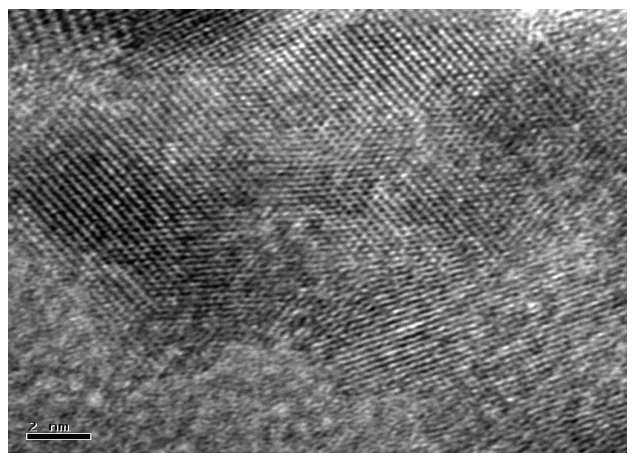

(b)

FIgURE 3: TEM and HRTEM image of ZnS:Y.

matched with the standard JCPDS data (Card no. 80-0020) [18]. Only diffraction peaks of $\mathrm{ZnS}$ are present in the XRD patterns due to the small doping amount of $\mathrm{Y}^{3+}$ impurity ions. No reflections related to $\mathrm{Y}^{3+}$ ions and other impurities were identified in the pattern, indicating the high purity of the final product. Due to size effect, the XRD peaks broaden and their widths become larger as the particles become smaller indicating the presence of nanometer regime. The size of the nanocrystals was determined by Debye-Scherer's equation [19]. From the X-ray line broadening the estimated average sizes of $\mathrm{ZnS}$ and $\mathrm{Y}^{3+}$ doped $\mathrm{ZnS}$ nanoparticles are around 6.8 and $8.1 \mathrm{~nm}$, respectively. This shows that the doped samples are slightly bigger than that of the undoped sample. For undoped $\mathrm{ZnS}$, the lattice constant has been calculated to be $5.362 \AA$, which is close to the standard value (5.345 $\AA$ ) reported in JCPDS file no. 80-0020, whereas, the lattice constant of doped $\mathrm{ZnS}$ sample (5.375 $\AA$ ) is larger than that of the undoped sample. This suggests that the possible substitution of $\mathrm{ZnS}^{2+}$ by $\mathrm{Y}^{3+}$ in the $\mathrm{ZnS}$ matrix results in the local distortion and dilation of crystal lattice as the ionic radius of $\mathrm{Y}^{3+}$ ion is $1.04 \AA$, which is bigger than $\mathrm{Zn}^{2+}$ ions which is $0.74 \AA$.

3.2. FESEM Analysis. The morphology of the as-prepared pure $\mathrm{ZnS}$ and doped metal sulfide nanoparticles was determined by FESEM analysis. Figure 2 shows the typical FESEM images of pure $\mathrm{ZnS}$ and $\mathrm{ZnS}: \mathrm{Y}$ samples which are spherical in structure and agglomerated. These micrographs indicate the presence of spherical agglomerates consisting of individual nanoparticles that are approximately in the range of $10-25 \mathrm{~nm}$ in size, which are composed of regular shape particles.

3.3. TEM Analysis. We can get direct information about particle size and morphology of the prepared nanocrystalline samples by analyzing TEM micrograph of the samples. However, a typical TEM image of $0.5 \mathrm{M} \mathrm{ZnS}: \mathrm{Y}$ sample is shown in Figure 3. TEM image clearly shows that the yttrium doped zinc sulfide has monodispersed spherical crystallites. The HRTEM image clearly revealed that the synthesized $\mathrm{ZnS}$ : Y nanoparticles have particle size of $\sim 4.5 \mathrm{~nm}$ as shown in Figure 3, which was corroborated with the XRD results. The nanoparticles are clearly well identified and no effective aggregation of bulk particles was formed. In the HRTEM image, lattice fringes can be clearly observed, which indicates that the particles are crystalline.

3.4. FTIR Spectra Analysis. FTIR spectral measurements have been made in the scan range of $400 \mathrm{~cm}^{-1}$ to $4000 \mathrm{~cm}^{-1}$. Before FTIR analysis the samples have been thoroughly mixed with $\mathrm{KBr}$ and palletized by pressing under a pressure of 10 tons for few minutes under vacuum. 


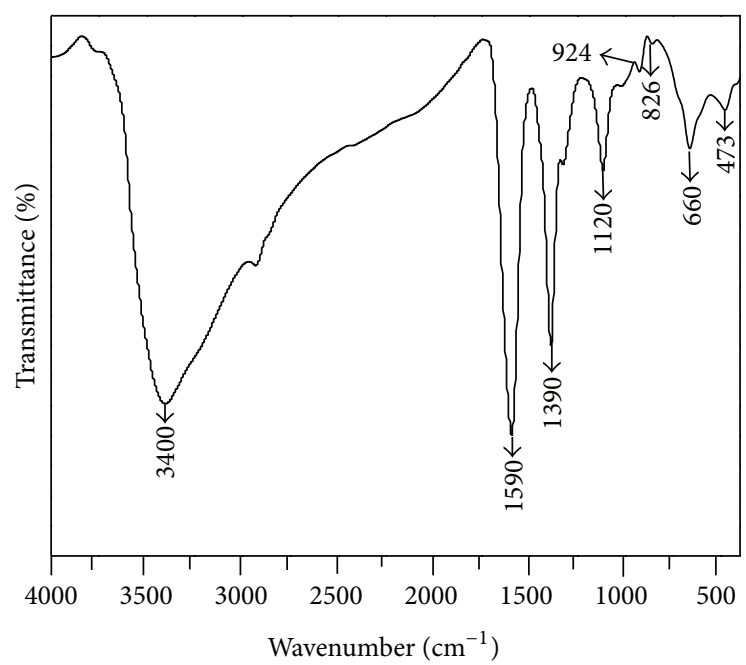

FIGURE 4: FTIR spectra of the as-prepared ZnS:Y.

FTIR spectra of the as-prepared ZnS:Y one are shown in Figure 4; FTIR peaks are assigned to samples at room temperature. IR spectra of the $\mathrm{ZnS}: \mathrm{Y}$ nanoparticles show a band at $3400 \mathrm{~cm}^{-1}$ attributed to the $\mathrm{O}-\mathrm{H}$ stretching vibration of water molecules [20]. As seen in our case vibration peak is observed at $1390 \mathrm{~cm}^{-1}$ which may be due to intercalated/adsorbed nitrate ions. Another peak observed at $1590 \mathrm{~cm}^{-1}$ corresponds to the $\mathrm{O}-\mathrm{H}$ bending of water molecules. Absorption at $1120 \mathrm{~cm}^{-1}$ was assigned to $\mathrm{SO}^{4-}$. Some weak additional bands observed at $924 \mathrm{~cm}^{-1}$ and $826 \mathrm{~cm}^{-1}$ indicate the presence of resonance interaction between vibrational modes of sulphide ions in the crystal [21]. Medium and strong band at $660 \mathrm{~cm}^{-1}$ are assigned to the $\mathrm{ZnS}$ band which is corresponding to sulphides [22]. The band at $472.2 \mathrm{~cm}^{-1}$ is assigned to the $\mathrm{Y}-\mathrm{O}$ [21]. Hence, the existence of above mentioned bands identify the presence of $\mathrm{ZnS}$ : $\mathrm{Y}$ along with the impurities that the samples consisted of water molecules or hydroxide ions.

3.5. Thermal Analysis. Thermogravimetric analysis (TGA) of $\mathrm{ZnS}: Y$ nanoparticles was performed on Perkin-Elmer TGA7 at a heating rate of $10^{\circ} \mathrm{C} \mathrm{min}^{-1}$ under nitrogen flow from room temperature (RT) to $800^{\circ} \mathrm{C}$. Differential scanning calorimetry (DSC) was performed on a NETZSCH DSC204 in nitrogen atmosphere at a heating rate of $10^{\circ} \mathrm{C} \mathrm{min}{ }^{-1}$.

Figure 5 represents the combined plots of TG and DSC. From the TG data, it is noticed that the weight loss of the nanoparticles are found to take place up to $700^{\circ} \mathrm{C}$. Figure 5 illustrates TGA curves of pure $\mathrm{ZnS}: \mathrm{Y}$ nanoparticles at a heating rate of $10^{\circ} \mathrm{C} \mathrm{min}{ }^{-1}$ under nitrogen atmosphere from 50 to $750^{\circ} \mathrm{C}$. Due to strong water absorption of $\mathrm{ZnS}$ [23], it adsorbs water from oxygen, which leads to the slight increase of mass at $50^{\circ} \mathrm{C}$. There are three obvious weight loss regions up to $800^{\circ} \mathrm{C}$. The first weight loss of $8 \%$ at around $120^{\circ} \mathrm{C}$ is due to evaporation of adsorbed moisture on the particles surface [24]. The second stage of weight loss starts at $300^{\circ} \mathrm{C}$ and can be seen up to $460^{\circ} \mathrm{C}$, which represents the evaporation and degradation of sulphuric acid group [25]. Further mass

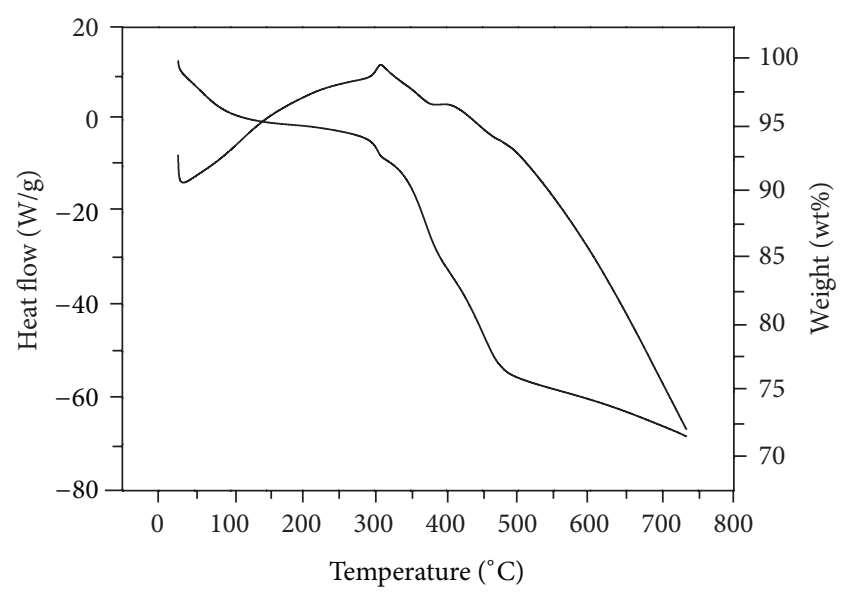

FIGURE 5: DSC and TG curve of ZnS:Y nanoparticles.

loss has been observed up to $700^{\circ} \mathrm{C}$, which inferred that $\mathrm{ZnS}$ is oxidized to $\mathrm{ZnO}$ [26]. It can be concluded that $\mathrm{ZnS}$ particles possess good thermal stability in oxygen. On the DSC curve, the first endothermic peak is found at $60^{\circ} \mathrm{C}$, which is attributed to the evaporation of the water. The endothermic peak around $230^{\circ} \mathrm{C}$ probably corresponds to the evaporation of organic and lattice deformation of $\mathrm{ZnS}: \mathrm{Y}$. The composition does not vary in the annealing range from $100^{\circ} \mathrm{C}$ to $200^{\circ} \mathrm{C}$, whereas, beyond $230^{\circ} \mathrm{C}$, the doped ions are released from the $\mathrm{ZnS}$ matrix. The observed exothermic peak at $310^{\circ} \mathrm{C}$ is believed to be the beginning of phase transition. A broad endothermic peak at $377^{\circ} \mathrm{C}$ may be due to decomposition of sulfur and release of doped ions from the $\mathrm{ZnS}$ matrix. An exothermic peak is exhibited at $410^{\circ} \mathrm{C}$, due to the crystallization of sample. Additionally, above $500^{\circ} \mathrm{C}$, there is a smooth downward trend in DSC curve with significant weight loss. This is may be due to release of residual sulfur ions from the sample.

3.6. Optical Absorption and Optical Band Gap Studies. After the suspension of pure $\mathrm{ZnS}$ and $\mathrm{ZnS}: \mathrm{Y}$ nanoparticles in liquid they were dried for $24 \mathrm{hrs}$ at $80^{\circ} \mathrm{C}$; then the sediment was dispersed in ethanol for UV absorption test (Figure 6). In our experiment, before the measurement starts ethanol was used as baseline calibration. A part of the sample solution was taken in quartz cuvette for absorption spectrum. The UV-visible absorption spectrums of these samples have been recorded in the range of 200 to $800 \mathrm{~nm}$ as shown in Figure 7. The absorption peaks were observed around 322 and $303 \mathrm{~nm}$ corresponding to pure $\mathrm{ZnS}$ and $\mathrm{ZnS}: \mathrm{Y}^{3+}$, respectively. However, the absorption peaks of undoped and $\mathrm{Y}^{3+}$ doped $\mathrm{ZnS}$ are considerably blue-shifted compared to that of bulk phase $\mathrm{ZnS}$ with absorption $340 \mathrm{~nm}(3.6 \mathrm{eV})$. This absorption shift is due to quantum size effect, representing a change in band gap along with excition features, resulting in a more discrete energy spectrum of the individual nanoparticles. The effect of the quantum confinement on impurity depends upon the size of the host crystal [27]. As the size of the host crystal decreases, the degree of confinement and its effect increases [28]. The band gap energy of the nanocrystals was calculated 


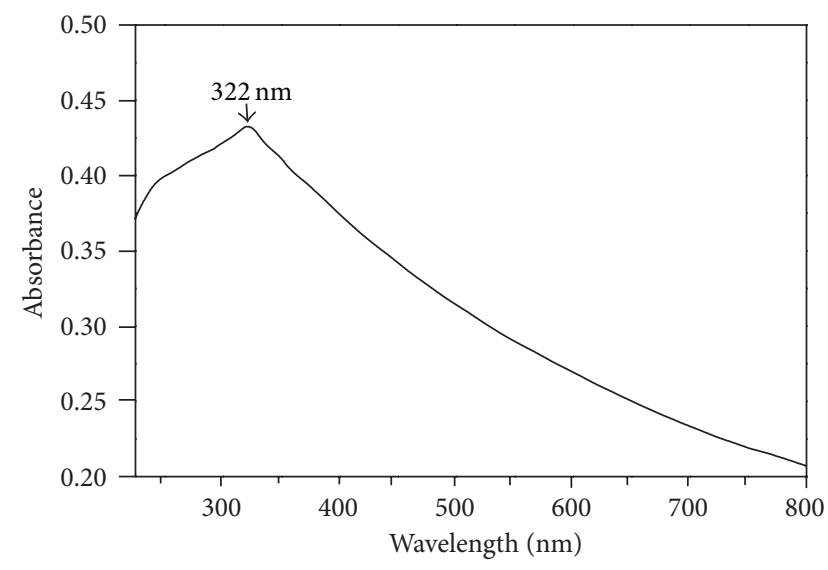

$-\mathrm{ZnS}$

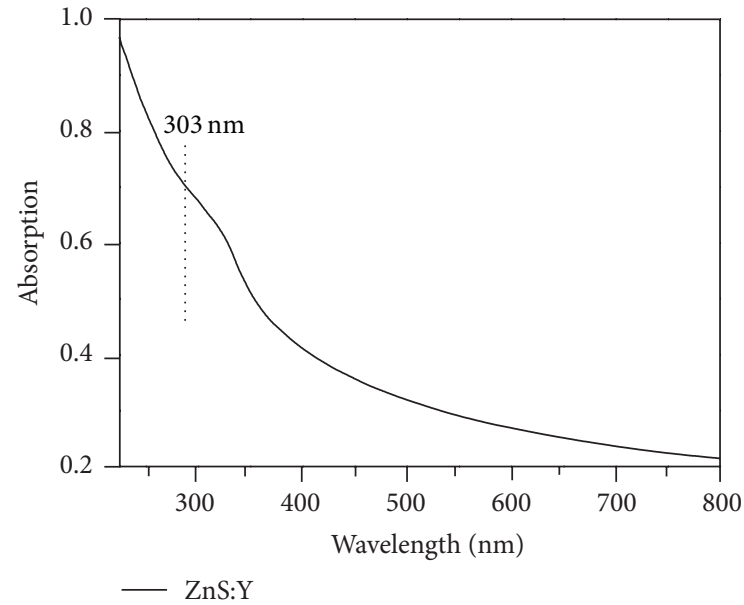

(b)

Figure 6: Optical absorption spectra of as-prepared sample pure $\mathrm{ZnS}$ and $\mathrm{ZnS}: \mathrm{Y}$.

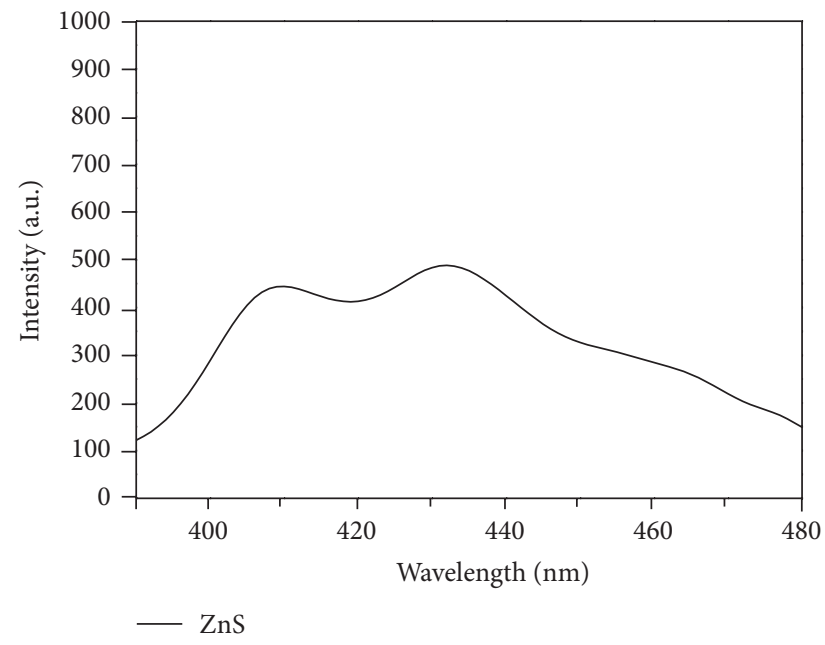

(a)

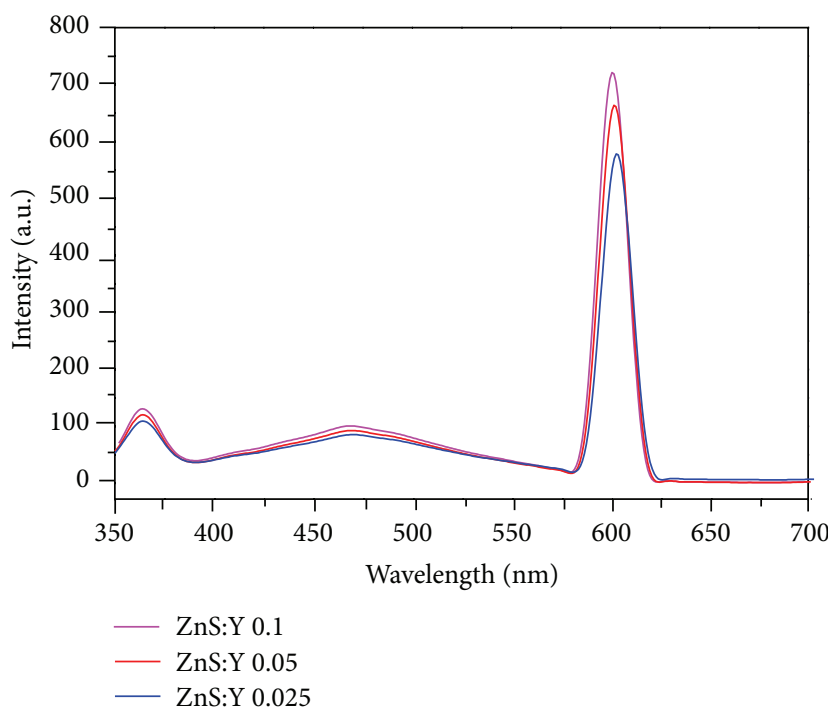

(b)

FIGURE 7: Photoluminescence emission spectra of pure $\mathrm{ZnS}$ and ZnS:Y.

from a simple energy wave equation. $E=h c / \lambda$ and the determined values are 3.85 and $4.09 \mathrm{eV}$ for undoped and $\mathrm{Y}^{3+}$ doped $\mathrm{ZnS}$, respectively. This result reveals that $\mathrm{ZnS}: \mathrm{Y}$ has a good absorption for light in the wavelength range of 200-340 nm and also size of the ZnS nanocrystals has been increased on doping.

3.7. Photoluminescence Study on ZnS:Y Nanoparticles. Figure 7 shows the room temperature PL spectra of pure $\mathrm{ZnS}$ and $\mathrm{ZnS}: \mathrm{Y}$ nanoparticles with an excitation wavelength of $325 \mathrm{~nm}$. From the PL spectra it was observed that pure $\mathrm{ZnS}$ nanoparticles showed only the blue self-activated (SA) luminescence emission peaks related with the point defects of the ZnS-host at 408 and $432 \mathrm{~nm}$. These peaks in blue region have been known due to the recombination of the electrons between the sulfur-vacancy-related donor and the valence band [29, 30]. A number of research groups [29-32] have studied the blue emission from $\mathrm{ZnS}$ nanoparticles under UV excitation. Usually for semiconductor nanocrystals, two emission peaks are observed which can be attributed to interstitial emission and the other trapped surface states emission, respectively [33]. The exciton emission peak is sharp and the trapped emission is broad [34].

Meanwhile, a comparison between the PL spectra of doped and undoped nanoparticles clearly revealed that, for all doped samples, there are three distinct emission bands in their PL spectra which are broad and asymmetric. However, on $\mathrm{Y}^{3+}$ doping blue emission of $\mathrm{ZnS}$ has completely quenched and three emission peaks at 363, 469, and $601 \mathrm{~nm}$ are generated due to the $5 \mathrm{~d}$ and $4 \mathrm{f}$ transition in $\mathrm{Y}^{3+}$ ions. The 
third emission peak at about $601 \mathrm{~nm}$ could be due to the incorporation of $\mathrm{Y}^{3+}$ ions into the $\mathrm{ZnS}$ host lattice. From the PL spectra it is also observed that as the $\mathrm{Y}^{3+}$ concentration increases the peaks were shifted slightly towards higher wavelength side; this is ascribed to the introduction of new occupied states by $\mathrm{Y}^{3+} 4 \mathrm{f}$ electrons that are located in the band gap of $\mathrm{ZnS}$ which causes the lattice distortion and thus influences the energy levels of defect states in $\mathrm{ZnS}$. One more noticeable feature is that the PL intensity of doped $\mathrm{ZnS}(0.025,0.05$, and 0.1$)$ nanoparticles significantly increases with increase in dopant concentration, which could be due to doping of rare earth ion in the host lattice. As the yttrium ions are incorporated, the intensity of this blue emission decreases and the orange emission comes up, since the energy transfer from $\mathrm{ZnS}$ host toward dopant centers is very efficient. With the increase in dopant concentration the orange band increases. In fact, reduction of blue band intensity is observed by varying the dopant concentration, which implies the decrease of the numbers of self-activated (SA) centers related with the $\mathrm{ZnS}$ lattice defects that can be related to increased number of dopant ions replacing the $\mathrm{Zn}$ ions. These results also demonstrate that dopant in host nanocluster can yield more efficient phosphors. Quenching of the $\mathrm{ZnS}$ emission and enhancement of the $\mathrm{Y}^{3+}$ emission demonstrates that $\mathrm{ZnS}$ nanocrystals absorbed energy from the excitation source and transferred it nonradiatively to luminescent centers $\left(\mathrm{Y}^{3+}\right)$ ions. Since the blue emission from $\mathrm{ZnS}$ results from recombination in the $\mathrm{ZnS}$ the energy transfer will be faster than hole trapping and recombination with electrons, the blue emission from $\mathrm{ZnS}$ is quenched and emissions from $\mathrm{Y}^{3+}$ are enhanced. Recently, similar type of quenching was also reported by Shanmugam et al. [35] for $\mathrm{Ce}^{3+}$ doped $\mathrm{ZnS}$ nanoparticles, in which the blue emission from $\mathrm{ZnS}$ was quenched and emissions from $\mathrm{Ce}^{3+}$ was enhanced. But the difficulty for the successful incorporation of rare earth ions in $\mathrm{ZnS}$ crystal lattice is due to the large mismatch in ionic radius and charge imbalance between two ions, that is, $\mathrm{Y}^{3+}$ and $\mathrm{Zn}^{2+}$ ions and higher coordination number of $\mathrm{Y}^{3+}$ in comparison with $\mathrm{Zn}^{2+}$ make the situation energetically unfavorable to replace majority of $\mathrm{Zn}^{2+}$ ions by $\mathrm{Y}^{3+}$ in $\mathrm{ZnS}$ lattice, subsequently producing symmetry distortion around $\mathrm{Y}^{3+}$. Recently, Pal et al. [18] reported a study showing that major fraction of $\mathrm{Eu}^{3+}$ ions occupies the $\mathrm{Zn}$ sites without inversion symmetry and produces red PL emission. Ashwini et al. [36] reported the PL studies on Eu:ZnS nanoparticles, in which $\mathrm{Eu}$ ions exist in $\mathrm{Eu}^{2+}$ state and also stated that in doped nanoparticles a large number of dopant centers are situated near the surface regions than in the interiors and hence are expected to give better emission efficiencies compared to pure $\mathrm{ZnS}$, which is due to a high surface-to-volume ratio based on their small particle size which favors the nucleation of the nanoparticles on the surface rather than interior of the samples. As a result the high surface-to-volume ratio causes the surface states to act as luminescent quenching centers [37]. But in our case the quenching of blue emission peak of $\mathrm{ZnS}$ has been observed and the peak intensity is also reduced, which indicated that the yttrium ions do not exist in $\mathrm{Y} 2+$ state. And in addition orange-yellow emission has been observed, which indicates the incorporation of $\mathrm{Y}^{3+}$ ions. Also, the literature reveals that $\mathrm{Y}$-doped $\mathrm{ZnO}$ exhibits an emission at $598 \mathrm{~nm}$ due to defects related to $Y$ elements [38]. According to these studies a part of $\mathrm{Y}^{3+}$ ions will occupy the $V_{\mathrm{Zn}}$ position to lower the $V_{\mathrm{Zn}}$ concentration which decreases the intensity of emission peak at $539 \mathrm{~nm}$. These studies also report that $Y$ ions exist in the $\mathrm{ZnO}$ lattices with +3 valence and they are apt to take the position of $\mathrm{Zn}$ ions which has a +2 valence; $\mathrm{Y}^{3+}$ is inevitable to attract more excess oxygen to be present in the $\mathrm{O}_{i}$ position so that the peak at $598 \mathrm{~nm}$ emission will be enhanced. This observation confirms that a part of $\mathrm{Y}^{3+}$ ions will occupy the $V_{\mathrm{Zn}}$ position at the lattice sites of $\mathrm{ZnS}$, which decreases the intensity of blue emission peaks by lowering the $V_{\mathrm{Zn}}$ concentration. From these studies we can say that $\mathrm{Y}$ ions exist in +3 valence states in $\mathrm{ZnS}$ lattices, which is foreseeable to produce the orange emission peak and intensity of these peaks increases with increase in yttrium concentration. There are no reports on PL data of ZnS:Y nanoparticles for comparison. These results provide an experimental method to modify the photoluminescence properties of $\mathrm{ZnS}$ by the introduction of yttrium dopants, which is important for both fundamental and applied points of view.

\section{Conclusion}

In this paper, we have reported a chemical coprecipitation method for the fabrication of pure $\mathrm{ZnS}$ and $\mathrm{ZnS}$ :Y nanoparticles using EDTA as a stabilizing agent. It was found that the $\mathrm{ZnS}$ and $\mathrm{ZnS}: \mathrm{Y}$ nanoparticles are highly crystalline and show zincblende structure. The XRD and HRTEM patterns indicated that the growth of the nanoparticles and the sizes of the nanocrystals were found to be $\sim 4.5 \mathrm{~nm}$. UVVisible absorption spectra showed a strong absorption peak at around $322 \mathrm{~nm}(3.85 \mathrm{eV})$ for pure $\mathrm{ZnS}$ and $332 \mathrm{~nm}(3.73 \mathrm{eV})$ for $\mathrm{ZnS}: \mathrm{Y}$, which are considerably blue-shifted compared to that of bulk phase $\mathrm{ZnS}(3.6 \mathrm{eV})$. This absorption shift indicated quantum size effect, representing a change in band gap along with edition features. The doping of $\mathrm{Y}^{3+}$ ions has tuned the band gap and photoluminescent properties of $\mathrm{ZnS}$ nanocrystallites. Photoluminescence studies showed strong and stable visible-light emissions in the visible spectrum with a broadening in the emission band. Undoped ZnS exhibits an emission maximum at 408 and $432 \mathrm{~nm}$, whereas on doping orange emission band was observed along with the blue emission bands at room temperature. The prepared $\mathrm{ZnS}: \mathrm{Y}^{3+}$ sample shows efficient emission of orange light with the peak emission $601 \mathrm{~nm}$ with the blue emission suppressed. A strong emission in the orange part of the visible spectrum was possible by doping the yttrium ions with zinc sulphide. The photoluminescence studies illustrated that the doping of $\mathrm{Y}^{3+}$ ions modifies the emission properties of nanocrystalline $\mathrm{ZnS}$ with increase in $\mathrm{Y}^{3+}$ ions concentration.

\section{Conflict of Interests}

The authors declare that there is no conflict of interests regarding the publication of this paper. 


\section{Acknowledgments}

One of the authors R. Viswanath gratefully acknowledges DST-Government of India, New Delhi, for providing INSPIRE fellowship-AORC (JRF-IF10176). The author also acknowledges IISc (Bangalore) for TEM and other spectral data of the samples and IIT (Kanpur) for FESEM images.

\section{References}

[1] K. N. Harish, H. S. Bhojya Naik, P. N. Prashanth Kumar, and R. Viswanath, "Synthesis, enhanced optical and photocatalytic study of Cd-Zn ferrites under sunlight," Catalysis Science \& Technology, vol. 2, pp. 1033-1039, 2012.

[2] K. N. Harish, H. S. Bhojya Naik, P. N. Prashanth Kumar, and R. Viswanath, "Remarkable optical and photocatalytic properties of solar light active Nd-substituted Ni ferrite catalysts: for environment protection," ACS Sustainable Chemistry \& Engineering, vol. 1, no. 9, pp. 1143-1153, 2013.

[3] E. R. Goldman, E. D. Balighian, M. K. Kuno et al., "Luminescent quantum dot-adaptor protein-antibody conjugates for use in fluoroimmunoassays," Physica Status Solidi B, vol. 229, no. 1, pp. 407-414, 2002.

[4] L. Wang, X. Xu, and X. Yuan, "Preparation and photoluminescent properties of doped nanoparticles of $\mathrm{ZnS}$ by solid-state reaction," Journal of Luminescence, vol. 130, no. 1, pp. 137-140, 2010.

[5] D. Amaranatha Reddy, G. Murali, B. Poornaprakash, R. P. Vijayalakshmi, and B. K. Reddy, "Effect of annealing temperature on optical and magnetic properties of $\mathrm{Cr}$ doped $\mathrm{ZnS}$ nanoparticles," Solid State Communications, vol. 152, no. 7, pp. 596-602, 2012.

[6] V. Ramasamy, K. Praba, and G. Murugadoss, "Synthesis and study of optical properties of transition metals doped $\mathrm{ZnS}$ nanoparticles," Spectrochimica Acta A, vol. 96, pp. 963-971, 2012.

[7] T. T. Nguyen, X. A. Trinh, L. H. Nguyen, and T. H. Pham, "Photoluminescence characteristics of as-synthesized and annealed $\mathrm{ZnS}: \mathrm{Cu}, \mathrm{Al}$ nanocrystals," Advances in Natural Sciences: Nanoscience and Nanotechnology, vol. 2, Article ID 035008, 2011.

[8] K. Manzoor, S. R. Vadera, N. Kumar, and T. R. N. Kutty, "Synthesis and photoluminescent properties of $\mathrm{ZnS}$ nanocrystals doped with copper and halogen," Materials Chemistry and Physics, vol. 82, no. 3, pp. 718-725, 2003.

[9] G. Murugadoss, B. Rajamannan, and V. Ramasamy, "Synthesis and photoluminescence study of PVA -capped ZnS: $\mathrm{Mn}^{2+}$ nanoparticles," Digest Journal of Nanomaterials and Biostructures, vol. 5, no. 2, pp. 339-345, 2010.

[10] N. Karar, F. Singh, and B. R. Mehta, "Structure and photoluminescence studies on ZnS:Mn nanoparticles," Journal of Applied Physics, vol. 95, no. 2, pp. 656-660, 2004.

[11] S. Sapra, A. Prakash, A. Ghangrekar, N. Periasamy, and D. D. Sarma, "Emission properties of manganese-doped $\mathrm{ZnS}$ nanocrystals," Journal of Physical Chemistry B, vol. 109, no. 5, pp. 1663-1668, 2005.

[12] W. Chen, V. F. Aguekian, N. Vassiliev, A. Y. Serov, and N. G. Filosofov, "New observations on the luminescence decay lifetime of $\mathrm{Mn}^{2+}$ in $\mathrm{ZnS}: \mathrm{Mn}^{2+}$ nanoparticles," The Journal of Chemical Physics, vol. 123, no. 12, Article ID 124707, 2005.
[13] M. Gao, J. Yang, L. Yang et al., "Enhancement of optical properties and donor-related emissions in Y-doped ZnO," Superlattices and Microstructures, vol. 52, no. 1, pp. 84-91, 2012.

[14] P. K. Sanoop, S. Anas, S. Ananthakumar, V. Gunasekar, R. Saravanan, and V. Ponnusami, "Synthesis of yttrium doped nanocrystalline $\mathrm{ZnO}$ and its photocatalytic activity in methylene blue degradation," Arabian Journal of Chemistry, 2012.

[15] J. Yang, R. Wang, L. Yang et al., “Tunable deep-level emission in $\mathrm{ZnO}$ nanoparticles via yttrium doping," Journal of Alloys and Compounds, vol. 509, no. 8, pp. 3606-3612, 2011.

[16] S. Anandan and S. Muthukumaran, "Influence of yttrium on optical, structural and photoluminescence properties of $\mathrm{ZnO}$ nanopowders by sol-gel method," Optical Materials, vol. 35, no. 12, pp. 2241-2249, 2013.

[17] H. Hu and W. Zhang, "Synthesis and properties of transition metals and rare-earth metals doped $\mathrm{ZnS}$ nanoparticles," Optical Materials, vol. 28, no. 5, pp. 536-550, 2006.

[18] M. Pal, N. R. Mathews, E. R. Morales, J. M. Gracia y Jimenez, and X. Mathew, "Synthesis of $\mathrm{Eu}^{+3}$ doped $\mathrm{ZnS}$ nanoparticles by a wet chemical route and its characterization," Optical Materials, vol. 35, no. 12, pp. 2664-2669, 2013.

[19] H. P. Klug and E. A. Leroy, X-Ray Diffraction Procedures, John Wiley \& Sons, New York, NY, USA, 1974.

[20] F. Vetrone, J. C. Boyer, and J. A. Capobianco, "Yttrium oxide nanocrystals: luminescent properties and applications," in Encyclopedia of Nanoscience and Nanotechnology, H. S. Nalwa, Ed., vol. 10, pp. 725-765, American Scientific Publishers, 2004.

[21] B. E. Prasad, P. V. Kamath, and S. Upadhya, "Electrochemical synthesis of macroporous oxide coatings on stainless-steel substrates," Journal of the American Ceramic Society, vol. 91, no. 12, pp. 3870-3874, 2008.

[22] B. S. Rema Devi, R. Raveendran, and A. V. Vaidyan, "Synthesis and characterization of $\mathrm{Mn}^{2+}$-doped $\mathrm{ZnS}$ nanoparticles," Pramana, vol. 68, no. 4, pp. 679-687, 2007.

[23] E. W. Wong, B. W. Maynor, L. D. Burns, and C. M. Lieber, "Growth of metal carbide nanotubes and nanorods," Chemistry of Materials, vol. 8, no. 8, pp. 2041-2046, 1996.

[24] N. Chandrakanthi and M. A. Careem, "Thermal stability of polyaniline," Polymer Bulletin, vol. 44, no. 1, pp. 101-108, 2000.

[25] A. L. Sharma, V. Saxena, S. Annapoorni, and B. D. Malhotra, "Synthesis and characterization of a copolymer: poly(anilineco-fluoroaniline)," Journal of Applied Polymer Science, vol. 81, no. 6, pp. 1460-1466, 2001.

[26] Y.-Y. She, J. Yang, and K.-Q. Qiu, "Synthesis of ZnS nanoparticles by solid-liquid chemical reaction with $\mathrm{ZnO}$ and $\mathrm{Na}_{2} \mathrm{~S}$ under ultrasonic," Transactions of Nonferrous Metals Society of China, vol. 20, supplement 1, pp. s211-s215, 2010.

[27] L. Laura Beecroft and K. Christopher Ober, "Nanocomposite materials for optical applications," Chemistry of Materials, vol. 9, no. 6, pp. 1302-1317, 1997.

[28] S. Kumara, N. Verma, and M. Singla, "Reflective characteristics of Ni doped Zns nanoparticle-pigment and their coatings," Chalcogenide Letters, vol. 8, no. 9, pp. 561-569, 2011.

[29] S. Lee, D. Song, D. Kim et al., "Effects of synthesis temperature on particle size/shape and photoluminescence characteristics of ZnS:Cu nanocrystals," Materials Letters, vol. 58, no. 3-4, pp. 342-346, 2004.

[30] W. Q. Peng, G. W. Cong, S. C. Qu, and Z. G. Wang, "Synthesis and photoluminescence of $\mathrm{ZnS}: \mathrm{Cu}$ nanoparticles," Optical Materials, vol. 29, no. 2-3, pp. 313-317, 2006. 
[31] N. Murase, R. Jagannathan, Y. Kanematsu et al., "Fluorescence and EPR characteristics of $\mathrm{Mn}^{2+}$-doped $\mathrm{ZnS}$ nanocrystals prepared by aqueous colloidal method," The Journal of Physical Chemistry B, vol. 103, no. 5, pp. 754-760, 1999.

[32] S. Yanagida, M. Yoshiya, T. Shiragami, C. Pac, H. Mori, and H. Fujita, "Semiconductor photocatalysis. I. Quantitative photoreduction of aliphatic ketones to alcohols using defect-free $\mathrm{ZnS}$ quantum crystallites," The Journal of Physical Chemistry, vol. 94, no. 7, pp. 3104-3111, 1990.

[33] B. Geng, J. Ma, and F. Zhan, "A solution phase thermal decomposition molecule precursors route to $\mathrm{ZnS}: \mathrm{Cu}^{2+}$ nanorods and their optical properties," Materials Chemistry and Physics, vol. 113, no. 2-3, pp. 534-538, 2009.

[34] M. O’Neil, J. Marohn, and G. McLendon, "Dynamics of electron-hole pair recombination in semiconductor clusters," The Journal of Physical Chemistry, vol. 94, no. 10, pp. 4356-4363, 1990.

[35] N. Shanmugam, S. Cholan, G. Viruthagiri, R. Gobi, and N. Kannadasan, "Synthesis and characterization of $\mathrm{Ce}^{3+}$-doped flowerlike ZnS nanorods," Applied Nanoscience, 2013.

[36] K. Ashwini, C. Pandurangappa, and B. M. Nagabhushana, "Synthesis and optical properties of undoped and Eu-doped ZnS nanoparticles," Physica Scripta, vol. 85, no. 6, Article ID 065706, 2012.

[37] W. Chen, J. Z. Zhang, and A. G. Joly, "Optical properties and potential applications of doped semiconductor nanoparticles," Journal of Nanoscience and Nanotechnology, vol. 4, no. 8, pp. 919-947, 2004.

[38] J. Yang, R. Wang, L. Yang et al., "Tunable deep-level emission in $\mathrm{ZnO}$ nanoparticles via yttrium doping," Journal of Alloys and Compounds, vol. 509, no. 8, pp. 3606-3612, 2011. 

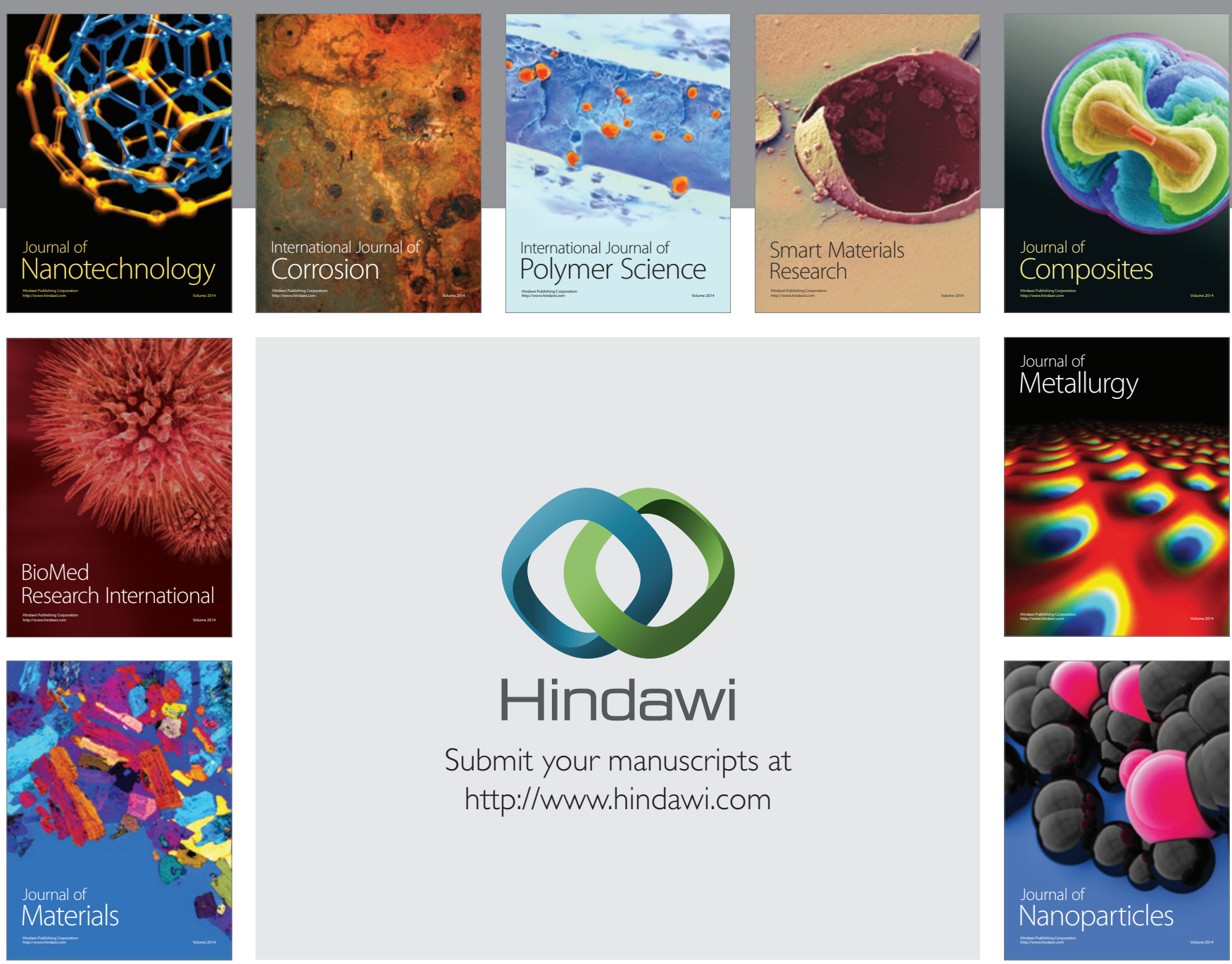

Submit your manuscripts at http://www.hindawi.com
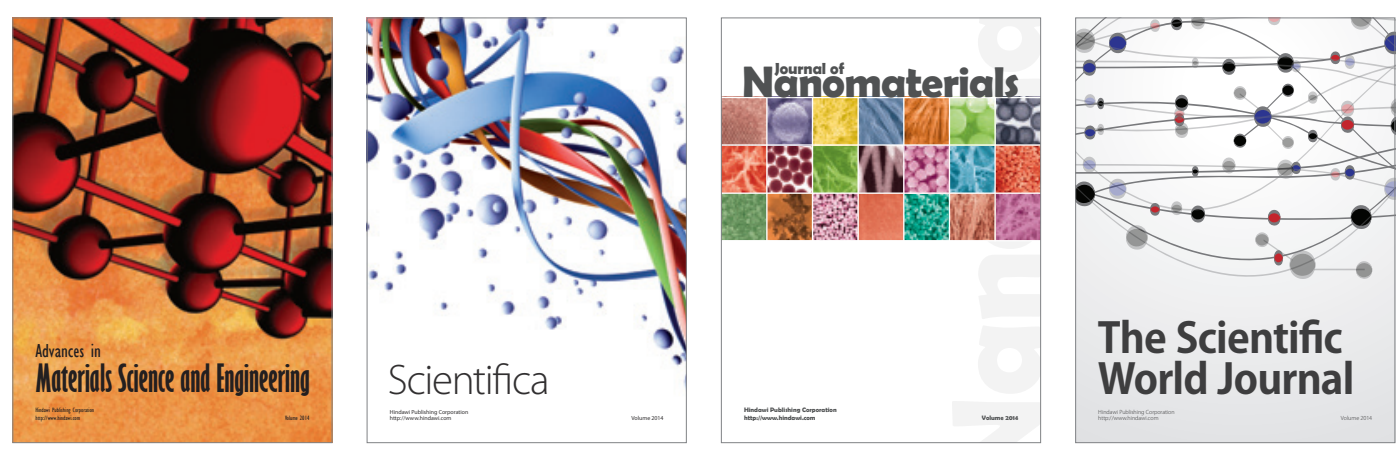

\section{The Scientific World Journal}
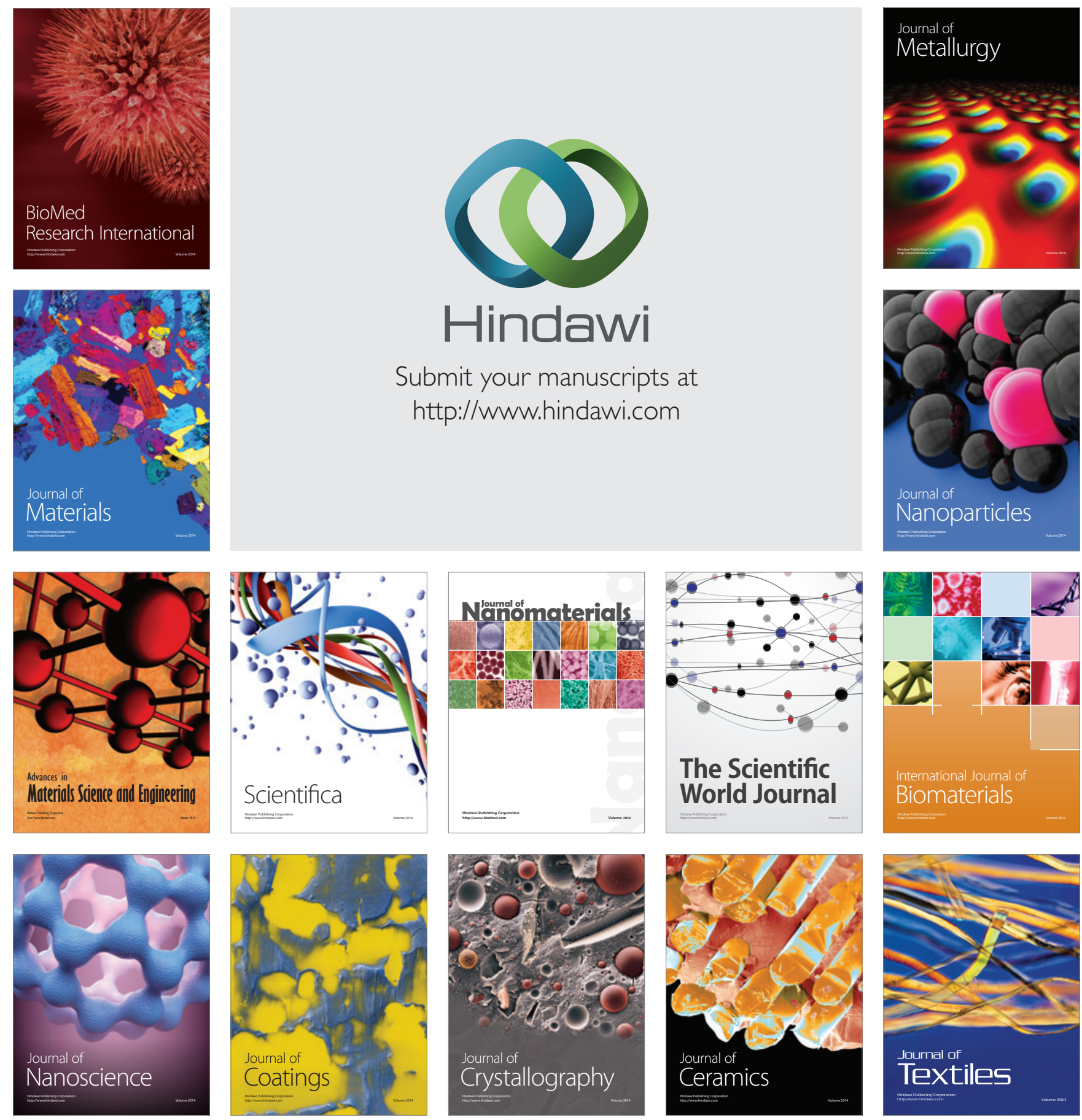